\title{
低合金鋼のオーステナイトにおけるニオブ炭化物 およびニオブ窒化物の溶解度
}

\author{
小山伸二* 石井輝 雄 ${ }^{*}$ 成田貴一*
}

Shinji Koyama, Teruo Ishii and Kiichi Narita : Solubility of Niobium Carbide and Nitride in Austenite of Low Alloy Steel. The solubilities of niobium carbide and nitride in iron austenite containing about $3 \% \mathrm{Ni}$ and $1.5 \% \mathrm{Cr}$ or $3 \% \mathrm{Ni}, 1.5 \% \mathrm{Cr}, 1 \% \mathrm{Mn}$ and $0.4 \% \mathrm{Si}$ have been measured by the method of equilibration with methane-hydrogen mixture gas or nitrogen.

The measured values of the solubility products of niobium carbide and nitride in the low-alloyed iron austenite agree approximately well with the calculated values obtained by adding arithmetically the part dependent on the content of alloying element in the logarithms of the solubility products of them in iron austenite containing each one of the elements. The results support the thermodynamic consideration on the solubility products of compounds in the multi-component solution.

(Received March 31, 1972)

\section{I. 緒言}

鉄罁の合金元素としての $\mathrm{Nb}$ の作用を考える上で，鋼中 に生成される $\mathrm{Nb}$ の炭化物ならびに窒化物の析出挙動を知 ることが重要である. そのために著者らは従来, その固溶一 析出反応について熱力学的検討をおこなってきた.

すなわち, 前報(1)(2) において $\mathrm{Mn}, \mathrm{Si}, \mathrm{Cr}$ あるいは $\mathrm{Ni}$ が それぞれ単独で共存する場合の $\gamma$ 鉄中にお打る $\mathrm{Nb}$ 炭化物 および窒化物の溶解度を測定し, 平衡濃度積を温度および これらの合金元素量の関数として表わした実験式を求め た.

本報ではこれらの元素が 2 種類以上同時に共存する場合 に, 前報で求めた実験式がその平衡濃度積の計算に適用で きるかどらかを検討することを目的として比較的に低合金 濃度組成の $\gamma$ 鉄中での $\mathrm{Nb}$ 炭化物および窒化物の溶解度を 測定した結果を報告する。

\section{II. 実 験 方 法}

$r$ 合金鉄中での $\mathrm{Nb}$ 炭化物ならびに窒化物の平衡濃度積 の測定方法の概略はつぎのとおりである.すなわち， $\mathrm{Cr}$ ， $\mathrm{Ni}, \mathrm{Mn}$ あるいは $\mathrm{Si}$ を一定量含む $\mathrm{Fe}$ 合金に $\mathrm{Nb}$ を〜 $0.5 \%$ の範囲で添加した試料を同時に所定分圧比の $\mathrm{CH}_{4} /$ $\mathrm{H}_{2}$ 混合ガスあるいは $1 \mathrm{~atm} の \mathrm{~N}_{2}$ ガスと平衡させる. 平衡 後の試料の全 $\mathrm{C}$ 量あるいは全 $\mathrm{N}$ 量を定量し, $\mathrm{Nb}$ 量との関 係を調べることにより $\mathrm{Nb}$ 炭化物あるいは窒化物が生成す るC 量あるいは $\mathrm{N}$ 量と $\mathrm{Nb}$ 量とを求めて，その值からそれ ぞれの平衡濃度積を求める方法である.

もちいた実験装置ならびに実験方法の詳細は前報(1) (2)の 場合と同じである.ただし本実験では $\mathrm{Nb}$ 窒化物の溶解度 測定の場合にも反応炉はタテ型として試料を吊り下げて

* 株式会社神戸製鋼所中央研究所 (Central Research Laboratory, Kobe Steel Ltd., Kobe)
$\mathrm{N}_{2}$ カスと反応させる万式をもちいた.

試料の作製方法も前報の場合と同じであり, 厚さ 0.25 $0.30 \mathrm{~mm}$, 幅 $10 \mathrm{~mm}$, 長さ $50 \sim 70 \mathrm{~mm}$ の試料を $\mathrm{CH}_{4} / \mathrm{H}_{2}$ 混合ガスあるいは $\mathrm{N}_{2}$ ガスと反応させた. 試料の化学成分 組成は Table 1 に示したとおりである.

Table 1 Chemical composition of specimen

\begin{tabular}{r|c|c|c|c|c}
\hline \hline Spec.No. & $\% \mathrm{Ni}$ & $\% \mathrm{Cr}$ & $\% \mathrm{Si}$ & $\% \mathrm{Mn}$ & $\% \mathrm{Nb}$ \\
\hline $\mathrm{NC}-\mathrm{A}-1$ & 3.00 & 1.51 & - & - & $-\overline{0}$ \\
-2 & 3.00 & 1.51 & - & - & 0.01 \\
-3 & 3.02 & 1.50 & - & - & 0.04 \\
-4 & 2.97 & 1.53 & - & - & 0.08 \\
-5 & 2.93 & 1.51 & - & - & 0.11 \\
-6 & 2.94 & 1.51 & - & - & 0.16 \\
-7 & 2.97 & 1.49 & - & - & 0.26 \\
-8 & 2.99 & 1.49 & - & - & 0.46 \\
\hline $\mathrm{NC}-\mathrm{B}-1$ & 2.96 & 1.50 & 0.36 & 0.99 & \\
-2 & 2.94 & 1.53 & 0.35 & 0.99 & 0.01 \\
-3 & 2.95 & 1.48 & 0.38 & 1.00 & 0.03 \\
-4 & 2.93 & 1.50 & 0.37 & 1.01 & 0.07 \\
-5 & 2.98 & 1.52 & 0.40 & 1.01 & 0.11 \\
-6 & 2.94 & 1.52 & 0.38 & 1.00 & 0.17 \\
-7 & 2.95 & 1.52 & 0.36 & 1.00 & 0.26 \\
-8 & 2.98 & 1.53 & 0.40 & 1.00 & 0.46 \\
\hline
\end{tabular}

\section{III. 実験結果および考察}

\section{1. $\gamma$ 合金鉄中における $\mathrm{Nb}$ 炭化物および 窒化物の溶解度}

所定分圧比の $\mathrm{CH}_{4} / \mathrm{H}_{2}$ 混合ガスと平衡させた場合の $\mathrm{Fe}$ $\mathrm{Cr}-\mathrm{Ni}-\mathrm{Nb}$ 合金ならびに Fe-Cr-Ni-Si-Mn-Nb 合金中での $\mathrm{C}$ 量と $\mathrm{Nb}$ 量との関係を測定した結果をとれぞれ Fig.1 お よび Fig.2 に示す.

Fig.1 および Fig.2 において, 特定の $\mathrm{Nb}$ 量以上の範囲 においてC量が急激に増加していることが認められる。こ

（1）小山，石井，成田：金属学会誌，35(1971)，698.

（2）小山, 石井, 成田: 金属学会誌, 35 (1971), 1089. 


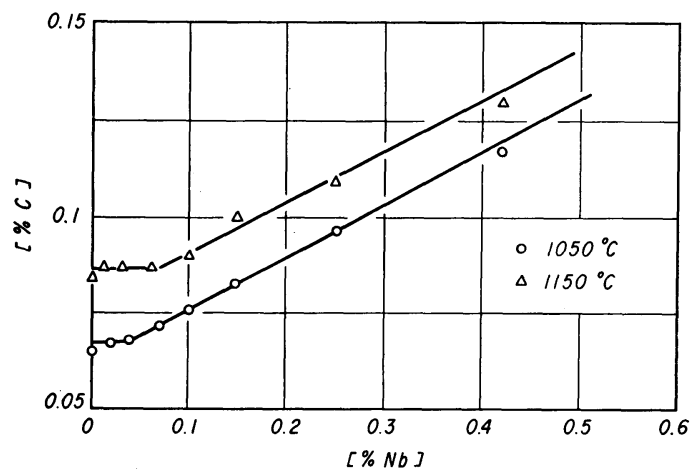

Fig.1 Relation between carbon and niobium content in $\mathrm{Fe}-\mathrm{Ni}-\mathrm{Cr}$ alloy equilibrated with $\mathrm{CH}_{4}-\mathrm{H}_{2}$ mixed gas

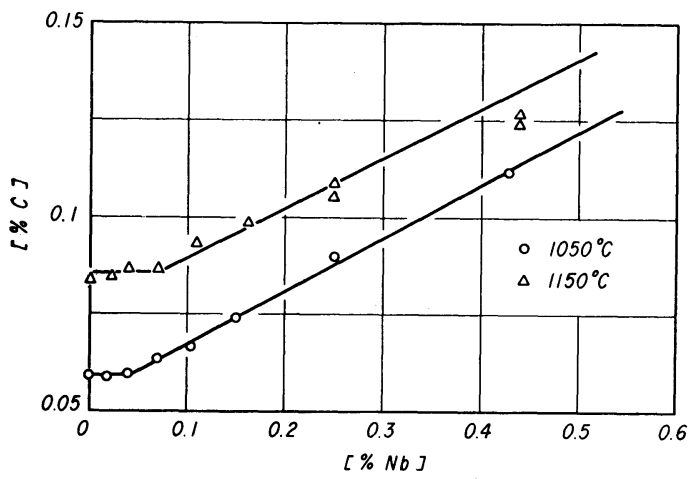

Fig.2 Relation ibetween carbon and niobium content in $\mathrm{Fe}-\mathrm{Ni}$-Cr-Si-Mn alloy equilibrated with $\mathrm{CH}_{4}-\mathrm{H}_{2}$ mixed gas

のことは, この Nb 量以上の範囲においては試料中に $\mathrm{Nb}$ 炭化物が生成していることを示している， Nb 炭化物の生 成範囲での直線の勾配から求めた $\mathrm{C} / \mathrm{Nb}$ の原子比はいずれ の場合にもほぼ 1 になり, 生成した炭化物の組成が基本的 には NbC とよく一致することを示している.これらの結果 から炭化物が生成しはじめる C 量と $\mathrm{Nb}$ 量とを図から読み とり平衡濃度積を求めた結果は Table 2 に実験値 (Exp. Value) として示したとおりである.

つぎに $1 \mathrm{~atm}$ の $\mathrm{N}_{2}$ ガスと平衡させた場合の $\mathrm{Fe}-\mathrm{Cr}-\mathrm{Ni}$ $\mathrm{Nb}$ 合金ならびに $\mathrm{Fe}-\mathrm{Cr}-\mathrm{Ni}-\mathrm{Si}-\mathrm{Mn}-\mathrm{Nb}$ 合金中の $\mathrm{N}$ 量と $\mathrm{Nb}$ 量との関係を測定した結果をそれぞれ Fig.3 扣よび Fig.4 に示す.

Table 2 Solubility products of $\mathrm{NbC}$ in $\mathrm{Fe}-\mathrm{Ni}-\mathrm{Cr}$ and $\mathrm{Fe}-\mathrm{Ni}-\mathrm{Cr}-\mathrm{Si}-\mathrm{Mn}$ alloy

\begin{tabular}{c|c|c|c|c}
\hline \multirow{2}{*}{ Specimen } & $\begin{array}{c}\text { Temp. } \\
\left({ }^{\circ} \mathrm{C}\right)\end{array}$ & \multicolumn{3}{|c}{$[\% \mathrm{Nb}] \cdot[\% \mathrm{C}] \times 10^{3}$} \\
\cline { 3 - 5 } & & Exp.value & $\begin{array}{c}\text { Calc.value Calc.value } \\
(1)\end{array}$ & $(2)$ \\
\hline Fe-Ni-Cr & 1050 & 3.52 & 3.66 & 3.69 \\
alloy & 1150 & 7.04 & 7.40 & 7.46 \\
\hline Fe-Ni-Cr- & 1050 & 3.60 & 3.99 & 4.00 \\
Si-Mn alloy & 1150 & 6.96 & 7.26 & 7.30 \\
\hline
\end{tabular}

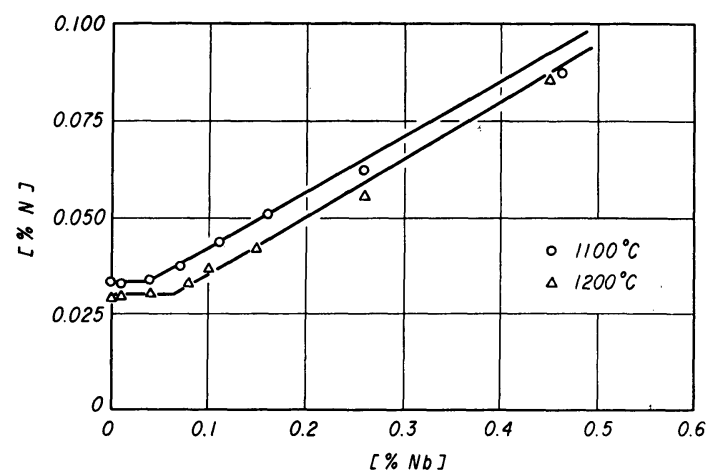

Fig.3 Relation between nitrogen and niobium content in $\mathrm{Fe}-\mathrm{Ni}-\mathrm{Cr}$ alloy equilibrated with $\mathrm{N}_{2}$ gas at 1atm

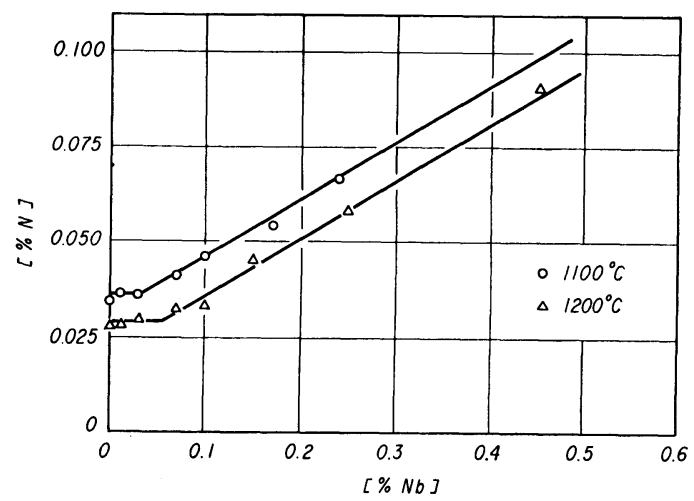

Fig.4 Relation between nitrogen and niobium content in $\mathrm{Fe}-\mathrm{Ni}-\mathrm{Cr}-\mathrm{Si}-\mathrm{Mn}$ alloy equilibrated with $\mathrm{N}_{2}$ gas at 1 atm

この場合にも，ある特定の $\mathrm{Nb}$ 量以上の範囲において $\mathrm{N}$ 量が急激に増加することが認められ，その範团では試料中 に窒化物が生成していることが示唆される，この範囲での 直線の勾配から求めた $\mathrm{N} / \mathrm{Nb}$ の原子比はほぼ 1 であり，生 成空化物の組成が $\mathrm{NbN}$ とく一致することを示してい る.これらの結果から $\mathrm{Nb}$ 窒化物の平衡濃度積を求めた結 果は Table 3 に実験值 (Exp. Value) として示す.

Table 3 Solubility products of $\mathrm{NbN}$ in $\mathrm{Fe}-\mathrm{Ni}-\mathrm{Cr}$ and $\mathrm{Fe}-\mathrm{Ni}-\mathrm{Cr}-\mathrm{Si}-\mathrm{Mn}$ alloy

\begin{tabular}{c|c|c|c|c}
\hline \hline \multirow{2}{*}{ Specimen } & $\begin{array}{c}\text { Temp. } \\
\left({ }^{\circ} \mathrm{C}\right)\end{array}$ & \multicolumn{3}{|c|}{$[\% \mathrm{Nb}] \cdot[\% \mathrm{~N}] \times 10^{3}$} \\
\cline { 3 - 5 } & Exp.value & $\begin{array}{c}\text { Calc.value } \\
(1)\end{array}$ & $\begin{array}{c}\text { Calc.value } \\
(2)\end{array}$ \\
\hline $\begin{array}{c}\text { Fe-Ni-Cr } \\
\text { alloy }\end{array}$ & 1100 & 1.32 & 1.33 & 1.41 \\
\hline $\begin{array}{c}\text { Fe-Ni-Cr- } \\
\text { Si-Mn alloy }\end{array}$ & 1100 & 2.10 & 2.24 & 2.02 \\
\hline
\end{tabular}

\section{2. $\gamma$ 合金鉄中における $\mathrm{Nb}$ 炭化物および窒化物の 平衡濃度積}

前報(1)(2) において, $\mathrm{Mn}, \mathrm{Si}, \mathrm{Cr}$ あるいは $\mathrm{Ni}$ の各元素が それぞれ単独で含まれる場合にも $r$ 鉄中に析出する $\mathrm{Nb}$ 炭 
化物ならびに窒化物は基本的にはそれぞれ $\mathrm{NbC}$ おび $\mathrm{NbN}$ の組成で表わされ，それらの平衡濃度積は温度およ び各元素の含有量の 1 次または 2 次の関数として与えられ ることを示した。 そして，これらの各元素の平衡濃度積に およぼす影響を固溶 $\mathrm{C}, \mathrm{N}$ ならびに $\mathrm{Nb}$ の活量に対する影 響を同時に含むものと考えて説明できることを示した。

上述の各元素が 2 種類以上同時に含まれる $\gamma$ 合金鉄中に おいても，III· 節に示したように析出する $\mathrm{Nb}$ 炭化物なら びに窒化物の基本組成はそれぞれ $\mathrm{NbC}$ および $\mathrm{NbN}$ と考 えてよい，すなわち，その固溶一析出反応はそれぞれ(1)和 よび (3) 式で表わされ，その平衡定数は (2)および (4)式 で示される.

$$
\begin{aligned}
& \mathrm{NbC}=\underline{\mathrm{Nb}}+\underline{\mathrm{C}} \\
& K=a_{\mathrm{Nb}} \cdot a_{\mathrm{C}} \\
& \mathrm{NbN}=\underline{\mathrm{Nb}}+\underline{\mathrm{N}} \\
& K=a_{\mathrm{Nb}} \cdot a_{\mathrm{C}}
\end{aligned}
$$

ここで， $a$ は重量\%で表わした活量であり，Henry 基 準での活量係数を $f$ とすれば一般的に $(5)$ 式で与えられ る.

$$
a_{i}=f_{i} \cdot[\% i]
$$

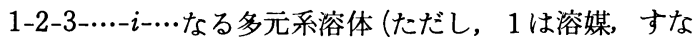
わち本研究の場合には Fe を表わす)に执いて溶質成分 $i の$ 活量係数 $f_{i}$ は一般に共存する溶質成分の濃度の関数で与 えられる。

$$
f_{i}=f_{i}(\% 2, \% 3, \cdots, \% i, \cdots)
$$

Wagner ${ }^{(3)}$ は溶質成分が比較的に稀薄な溶体について活 量係数の Taylar 級数展開式をもちいて（7)式の関係式を 導いている。

$$
\begin{aligned}
\log f_{i} & =\frac{\partial \log f_{i}}{\partial[\% 2]} \cdot[\% 2]+\frac{\partial \log f_{i}}{\partial[\% 3]} \cdot[\% 3]+\cdots \\
& +\frac{\partial \log f_{i}}{\partial[\% i]} \cdot[\% i]+\cdots+\frac{1}{2} \cdot \frac{\partial^{2} \log f_{i}}{\partial[\% 2]^{2}} \cdot[\% 2]^{2} \\
& +\frac{\partial^{2} \log f_{i}}{\partial[\% 2] \partial[\% 3]}[\% 2][\% 3]+\cdots+\cdots
\end{aligned}
$$

(7) 式に打いて，稀薄容体については 2 次以上の偏微係 数の項を無視できるものとすれば, 活量係数 $f_{i}$ はいわゆ る相互作用助係数 $e_{i}^{(j)}$ をちいて溶質成分濃度の 1 次の関 数で与えられる.

$$
\begin{gathered}
\log f_{i}=\sum_{j=2}^{m} e_{i}^{(j)} \cdot[\% j] \\
\text { こで, } e_{i}^{(j)} \equiv\left(\frac{\partial \log f_{i}}{\partial[\% j]}\right)_{[\% 1] \rightarrow 100} \text { である. }
\end{gathered}
$$

（8）式の関係から多元系の無限稀薄溶体においては成分 $i$ の活量係数の対数については単純な加算性が成立するこ とが期待される．ただし，一般的には溶質成分のある有限 濃度に打いて多元系溶体の活量俰数を計算する場合に， 3 元系溶体に打いて求めた相互作用助係数の值をそのままも

(3) C.Wagner : Thermodynamics of Alloys, Addison Wesley Press, (1952), 51.
ちいて加算性が成立するといら保証はない，しかしなが ら,たとえば数\%までの $\mathrm{Cr}, \mathrm{Ni}$ およびWを含む多元系の $r$ 合金鉄中でのNの活量俰数は，それぞれの元素を単独で含 む 3 元系合金鉄において求めた相互作用助係数をむちいて (8) 式の関係からほぼ推定しらることが報告 ${ }^{(4)}$ されてお り, また本報告でも後述するように 4 元以上の多元系溶体 でのCあるいはNの活量係数の計算に近似的には（8)式が 適用できる。このように溶質成分が比較的に低濃度範囲で は(8)式は有効な近似式であると考学られる。

つぎに $(7)$ 式において，比較的に溶質成分の高濃度溶体 については 2 次の偏微保数の項までを考慮すれば, 活量係 数は (9) 式で表わされる(5).

$$
\begin{aligned}
\log f_{i} & =\sum_{j=2}^{m} e_{i}^{(j)} \cdot[\% j]+\sum_{j=2}^{m} r_{i}^{(j)} \cdot[\% j]^{2} \\
& +\sum_{\substack{j=2 \\
j \\
j \neq k}}^{m} \sum_{\substack{k=2 \\
j \neq k}}^{(j, k)} \cdot[\% j] \cdot[\% k]
\end{aligned}
$$

この場合には，一般的に式の上でも単純な加算性が成立 することは期待できない．しかし(9)式において右辺第 3 項, 寸なわち成分 $j$ と $k$ 濃度の積の関与する項が近似的 に無視できるものとす礼ば，多元系溶体において成分 $i$ の 活量係数に対する成分 $j$ の影響をその濃度の 2 次の関数で 与えて，それぞれを加算して近似的に推定できる場合が考 えられる．ここで，本研究の場合には成分 $i$ は $\mathrm{Nb}, \mathrm{C}$ ある いはNに相当し，成分 $j$ は $\mathrm{Mn}, \mathrm{Si}, \mathrm{Cr}$ あるいは $\mathrm{Ni}$ に相当 する.

(2)および (4) 式と (5) 式の関係から $\mathrm{Mn}, \mathrm{Si}, \mathrm{Cr}$ およ び $\mathrm{Ni}$ などの元素が 2 種類以上同時に含まれる $\gamma$ 合金鉄中 での $\mathrm{Nb}$ 炭化物あるいは窒化物の平衡濃度積も $\mathrm{Nb}$ と C るいはNの活量に対するとれらの共存元素の影響を考虑し て求められると考えられる.

前報(1)(2) で報告したように $\mathrm{Mn}, \mathrm{Si}, \mathrm{Cr}$ あるいは $\mathrm{Ni}$ が それぞれ単独で含まれる場合の $\gamma$ 合金鉄中での $\mathrm{Nb}$ 炭化物 あるいは窒化物の平衡濃度積 $\left(K^{\prime}\right)$ はある一定温度では共 存元素濃度の 1 次または 2 次の関数として $\log K^{\prime}=A+B_{j}$ $[\% j]$ または $\log K^{\prime}=A+B_{j}[\% j]+C_{j}[\% j]^{2}$ の形の式で与 えられまたこの式をさらに温度の関数としてまとめれば $\log K^{\prime}=(A / T+B)+\left(A_{j}^{\prime} / T+B_{j}^{\prime}\right) \cdot[\% j]$

または

$$
\begin{aligned}
\log K^{\prime} & =(A / T+B)+\left(A_{j}^{\prime} / T+\dot{B_{j}}\right) \cdot[\% j] \\
& +\left(A_{j}^{\prime \prime} / T+B_{j}^{\prime \prime}\right) \cdot[\% j]^{2}
\end{aligned}
$$

の形の式で表わされる.ここで $A, B$ は定数であり，添字 $j$ をつけたものは共存元素 $j$ の種類によって異なる定数で ある. $T$ は絶対温度を示す。これらの式において共存元素 濃度に依存する項は $\mathrm{Nb}$ とCないしは $\mathrm{N}$ の活量に対する $j$ 元素の影響をまとめたものに相当すると考えると， 2 種類

(4) 一瀬 : 京都大学工学部学位論文, (1969), 72 .

(5) C.H.P.Lupis and J.F.Elliott : Acta Met., 14 (1966), 529 . 
以上の共存元素が同時に含まれる多元系 $\gamma$ 合金鉄での $\mathrm{Nb}$ 炭化物あるいは窒化物の平衡濃度積は前報で求めた平衡濃 度積の各共存元素濃度に依存する項を加算することによっ て近似的に推定できると考えられる．たとえば $\mathrm{Fe}-\mathrm{Cr}-\mathrm{Ni}$ 合金の場合には

$$
\begin{aligned}
\log K^{\prime} & =(A / T+B)+\left(\overrightarrow{A_{\mathrm{Cr}}} / T+\dot{B_{\mathrm{Cr}}}\right) \cdot[\% \mathrm{Cr}] \\
& +\left(\ddot{A_{\mathrm{Cr}}} / T+\ddot{B_{\mathrm{Cr}}}\right) \cdot[\% \mathrm{Cr}]^{2}+\left(A_{\mathrm{Ni}}^{\prime} / T+B_{\mathrm{Ni}}^{\prime}\right) \cdot[\% \mathrm{Ni}] \\
& +\left(\ddot{A_{\mathrm{Ni}}} / T+\dot{B_{\mathrm{Ni}}}\right) \cdot[\% \mathrm{Ni}]^{2}
\end{aligned}
$$

によって平衡濃度積を計算できる。このような考え方にし たがって，本実験の多元系 $r$ 合金鉄での $\mathrm{Nb}$ 炭化物あるい は窒化物の平衡濃度積を計算した值を，それぞれ前揭の Table 2 あるいは Table 3 そ Calc.Value として実験値と 比較して示した.なお，同表において Calc. Vaue (1)として 示した値は，前報で温度および共存元素濃度の関数式とし てまとめた実験式をもちいた場合の計算値であり，Calc． Value (2) は各実験温度において共存元素濃度の関数式と して求めた実験式をもちいた場合の計算値である. 実験值 と計算值とは比較的によく一致しており，本実験のように 比較的に低合金濃度組成では，多元系 $\gamma$ 合金鉄中での $\mathrm{Nb}$ 炭化物あ者いは窒化物の平衡濃度積を前述の考方方にもと づいてそれぞれの共存元素が単独で含まれる場合の平衡濃 度積から近似的に推定することができる。

\section{3. $\gamma$ 合金鉄中における炭素および窒素の溶解度}

III $\cdot 2$ 節に打いて $\mathrm{Mn}, \mathrm{Si}, \mathrm{Cr}$ あるいは $\mathrm{Ni}$ が 2 種類以上 含まれる比較的に低濃度組成の $r$ 合金鉄中における $\mathrm{Nb}$ 炭 化物あるいは窒化物の平衡濃度積はこれらの共存元素の $\mathrm{Nb}$ とあるいはNの活量に対する影響を考えることによ って, 各共存元素が単独で含まれる場合の平衡濃度積から 近似的に推定できることを示した。そ場合に多元系溶体 での溶質元素の活量係数が 3 元系溶体での相互作用係数の 積で表わされることを仮定している。 この仮定の妥当性を 検討するために，CあるいはN活量一定の気相と平衡させ た場合の $\mathrm{Fe}-\mathrm{Ni}-\mathrm{Cr}$ 扰よび $\mathrm{Fe}-\mathrm{Ni}-\mathrm{Cr}-\mathrm{Si}-\mathrm{Mn}$ 合金の $\gamma$ 相 に淤けるC あるいは 報(1) (2) で求めた $\mathrm{Mn}, \mathrm{Si}, \mathrm{Cr}$ あるいは $\mathrm{Ni}$ が単独で共存する 場合のCあるいはNの相互作用助係数の值をもちいて(8) 式の関係式から活量係数を求めて, 等活量の気相と平衡さ せた純鉄のCあるいはNの溶解度から計算した $\mathrm{Fe}-\mathrm{Ni}-\mathrm{Cr}$ 合金 (Table 1 に示した試料 NC-A-1) および Fe-Ni-Cr-
Si-Mn 合金 (同じく試料 NC-B-1) のCあるいはNの溶解度 を実測值と比較した，その結果はそれぞれ Table 4 あるい は Table 5 に示したと拈りである。

Table 4 Carbon content in $\mathrm{Fe}-\mathrm{Ni}-\mathrm{Cr}$ and $\mathrm{Fe}-\mathrm{Ni}$ - $\mathrm{Cr}$ -

\begin{tabular}{|c|c|c|c|}
\hline \multirow{2}{*}{ Specimen } & \multirow{2}{*}{$\underset{\left({ }^{\circ} \mathrm{C}\right)}{\text { Temp. }}$} & \multicolumn{2}{|c|}{$[\% \mathrm{C}]$} \\
\hline & & Exp.value & Calc. value \\
\hline $\begin{array}{l}\mathrm{Fe}-\mathrm{Ni}-\mathrm{Cr} \\
\text { alloy }\end{array}$ & $\begin{array}{l}1050 \\
1150\end{array}$ & $\begin{array}{l}0.065 \\
0.085\end{array}$ & $\begin{array}{l}0.068 \\
0.085\end{array}$ \\
\hline $\begin{array}{l}\mathrm{Fe}-\mathrm{Ni}-\mathrm{Cr}-\mathrm{Si}-\mathrm{Mn} \\
\text { alloy }\end{array}$ & $\begin{array}{l}1050 \\
1150\end{array}$ & $\begin{array}{l}0.060 \\
0.085\end{array}$ & $\begin{array}{l}0.061 \\
0.085\end{array}$ \\
\hline
\end{tabular}
$\mathrm{Si}-\mathrm{Mn}$ alloy equilibrated with $\mathrm{CH}_{4}-\mathrm{H}_{2}$ mixed gas at fixed $P_{\mathrm{CH}_{4}} / P_{\mathrm{H}_{2}}$

Table 5 Nitrogen content in $\mathrm{Fe}-\mathrm{Ni}-\mathrm{Cr}$ and $\mathrm{Fe}-\mathrm{Ni}-\mathrm{Cr}$ Si-Mn alloy equilibrated with $\mathrm{N}_{2}$ gas at $1 \mathrm{~atm}$

\begin{tabular}{c|c|c|c}
\hline \hline \multirow{2}{*}{ Specimen } & \multirow{2}{*}{$\begin{array}{c}\text { Temp. } \\
\left({ }^{\circ} \mathrm{C}\right)\end{array}$} & \multicolumn{2}{|c}{$[\% \mathrm{~N}]$} \\
\cline { 3 - 4 } & & Exp.value & Calc.value \\
\hline Fe-Ni-Cr & 1100 & 0.0334 & 0.0323 \\
alloy & 1200 & 0.0298 & 0.0280 \\
\hline $\begin{array}{c}\text { Fe-Ni-Cr-Si-Mn } \\
\text { alloy }\end{array}$ & 1100 & 0.0340 & 0.0325 \\
& 1200 & 0.0280 & 0.0286 \\
\hline
\end{tabular}

計算値と実測值とはよく一致しており，このような比較 的に低濃度組成の多元系溶体の CあるいはNの活量係数に 関しては (8)式の関係が注涪成立することが推定される.

\section{IV. 結言}

$1 \% \mathrm{Mn}, 0.4 \% \mathrm{Si}, 1.5 \% \mathrm{Cr}$ および $3 \% \mathrm{Ni}$ を含む $\mathrm{Fe}$ $\mathrm{Cr}-\mathrm{Ni}$ および $\mathrm{Fe}-\mathrm{Cr}-\mathrm{Ni}-\mathrm{Si}-\mathrm{Mn}$ 合金の $r$ 相領域に拈ける $\mathrm{Nb}$ 炭化物および窒化物の溶解度を測定した結果。このよ らな比較的に低合金濃度範囲の多元系溶体における平衡濃 度積は，Nb とCあるいはNの活量に対するこれらの各合 金元素の影響を考虑することによって各元素が単独で含ま れる場合の平衡濃度積から各合金元素濃度に依存する項を 加算することによって近似的に推定できることをあきらか にした。

また，活量一定の気相と平衡させた場合のCあるいはN の溶解度に関しても Wagner が導いた多元系溶体中の溶質 元素の活量係数に関する理論式をもちいてほぼ推定できる ことを示した. 